\title{
ANTIMALARIAL, FERRIC REDUCING ANTIOXIDANT POWER AND ELEMENTAL ANALYSIS OF Caesalpinia pulcherrima LEAF EXTRACT
}

\author{
O. K. Ogbeide ${ }^{1}$, O. K. Okhomina ${ }^{1}$, I. G. Omoregie ${ }^{1}$, C. A. Unuigbe ${ }^{1}$, A. Ighodaro ${ }^{1}$, I. U. Akhigbe ${ }^{1}$, C. \\ M. Iheanacho' ${ }^{1}$ P. C. Akubuiro' ${ }^{1}$, A. Solomon ${ }^{1}$, E. E. I. Irabor' ${ }^{1}$, B. J. Owolabi ${ }^{1,2}$, A. Falodun ${ }^{3}$ \\ ${ }^{1}$ Department of Chemistry, Faculty of Physical Sciences, University of Benin, Benin City, Nigeria. \\ ${ }^{2}$ Department of Chemistry, School of Sciences, the Federal University of Technology, Akure, Nigeria. \\ ${ }^{3}$ Department of Pharmaceutical Chemistry, Faculty of Pharmacy, University of Benin, Benin City, \\ Nigeria.
}

*Corresponding Author's email: kennedy.ogbeide@ uniben.edu Tel.: +2348055949282

Received 19 June 2020; accepted 29 June 2020, published online 06 July 2020

Abstract

The increasing rise of resistance of malaria parasites to established antimalarial drugs have necessitated the continued search for new drug entities especially those with fresh modes of action. Caesalpinia pulcherrima is a plant with many pharmacological and medicinal properties. The leaf extract and fractions were studied for their antimalarial, ferric reducing antioxidant power and elemental composition.Various fractions of the leaf extracts were obtained using vacuum liquid chromatography (VLC). The in vivo antimalarial activity was evaluated against plasmodium berghei parasites. The required dose was given according to the weight of the animal two hours after inoculation of parasites on $D_{1}$, then once daily for three more days $\left(D_{2}-D_{4}\right)$. The antioxidant activity was carried out using $U V$ Visible spectrometer at $593 \mathrm{~nm}$. The elemental analysis was done using Atomic Absorption Spectrophotometer. There was a dose dependent increase in percentage chemo-suppression of the parasites by the different groups with maximum effect at $800 \mathrm{mg} / \mathrm{kg}$ (61.57-34.86 \% from day five (5)to day eight (8) respectively). The highest FRAP activity was observed in $100 \%$ ethyl acetate with $314.90 \pm$ $3.94 \mathrm{mmol}$, while the lowest antioxidant power was observed in 50\% ethyl acetate:50\% n-hexane fraction with $48.50 \pm 1.10$. 90\%methanol:10\% distilled water fraction did not indicate any FRAP activity. The results obtained revealed that the phytochemicals with very potent antioxidant power are more present in the ethyl acetate fraction. Elemental compositions (ppm) in the powdered leaf of $C$. pulcherrima were, sodium ( $\mathrm{Na}) ; 20.27 \pm 0.12$, iron $(\mathrm{Fe}) ; 13.50 \pm 0.08$, calcium $(\mathrm{Ca}) ; 9.0 \pm 0.14$, and copper $(\mathrm{Cu}) ; 0.30 \pm 0.08$. Lead $(\mathrm{Pb})$ was not detected. This study has shown that Lead concentration was below detectable limit, while the concentrations of $\mathrm{Fe}$ and $\mathrm{Cu}$ were within established permissible limits. Appreciable amount of $\mathrm{Na}$ and $\mathrm{Ca}$ were also indicated. $\mathrm{C}$. pulcherrima leaf extract and fractions contain biologically active principles that are relevant antimalarial and antioxidant agents with acceptable mineral compositions.

Key words: Caesalpinia pulcherrima, antimalarial, antioxidant power, elemental composition

\section{Introduction}

Malaria is one of the most life-threatening infectious diseases worldwide, claiming the lives of millions of people each year [1]. It is an acute and chronic tropical infection caused by a parasite of the genus Plasmodium [2]. There are five species that can cause human malaria: $P$. falciparum, $P$. vivax, $P$. malariae, and $P$. ovale and $P$ knowlesi [2]. The female mosquitoes of the genus Anopheles transmit the protozoa to humans. Some signs and symptoms of the illness are high fever, chills, headache, anemia, and splenomegaly [2]. Most serious and fatal complications are caused by $P$. falciparum [2]. 
Majority of the human race, especially from developing countries depend on the traditional system of medicine for the management of various diseases [3]. Medicinal plants, herbs and algae are naturally provided remedies to cure disease with negligible side effects [4]. They are also a pool of new and fresh antioxidants principally those with high phenolic contents [5]. Hence there is an everincreasing concern in natural antioxidants from food, predominantly vegetables and fruits. Several public health reports support their protecting effects against many diseases [6-8]. Oxidative stress is implicated in the pathophysiology of malaria. Plasmodium parasites digest haemoglobin leading to the production of heme. Heme triggers the production of ROS which are involved in the pathophysiology of malaria $[9,10]$ and can lead to the development of anemia $[11,12]$ and apoptosis [13]. All these are implicated in the pathogenic mechanisms triggered by the parasite [14] as well as free radical production [15] and antioxidant defenses [16] in host cells to prevent or stop an infection.

A free radical can be defined as any molecular species capable of independent existence that contains an unpaired electron in an atomic orbital; some free radicals arise normally during metabolism [17]. Other sources are pollution, radiation, herbicides, cigarette smoke, stress, lack of exercise and lack of sleep leading to oxidative stress. Oxidative stress is a term used to explain the oxidative damage (chain reaction) resulting when a free radical attacks a stable molecule. An antioxidant is defined as molecules stable enough to donate an electron to free radicals and terminate the chain reaction before vital molecules are damaged [17].

Caesalpinia pulcherrima $(\mathrm{CP})$ is a flowering plant in the legume family fabaceae. They are normally grown as ornamental flowers in tropical gardens $[18,19]$. The plant is known to be a rich source of cassane-type diterpenoids, lupeol, lupeol acetate, carotenoids, quercetin, rutin, beta sitosterol, glycosides, phenols, steroids, flavonoids and alkaloids [19, 20-23]. Different researchers have reported the antiplasmodial activities of the leaves and stem bark of CP [19, 21, 22]. In these studies, the leaves of $\mathrm{CP}$ were shown to exhibit moderate antiplasmodial activity against Plasmodium berghei (PB), while the stem bark showed significant antiplasmodial effects [19, 21]. In spite of these recognized arrays of reports on the therapeutic and pharmacological potentials of this plant, there is yet a scarcity of information on the in vivo antiplasmodial activity on the extracts from the leaves of $C$. pulcherrima. Therefore, this study aims to investigate the in vivo antiplasmodial potentials, ferric reducing antioxidant power and elemental content of $C$. pulcherrima leaf extract, in order to validate its ethnomedicinal use in the treatment of human malaria infection in the tropics.

\section{Materials and Methods \\ Sample collection and preparation}

Fresh leaves of $C$. pulcherrima were collected on April, 2016 at the University of Benin. The plant was identified in the Department of Pharmacognosy, Faculty of Pharmacy, University of Benin. The leaves were dried at ambient temperature and were ground to powder by a mechanical grinder. The powdered leaves were stored in an air-tight container and kept for further analysis.

\section{Determination of some metals in c. Pulcherrima}

The Sample ( $1 \mathrm{~g})$ was digested with concentrated nitric acid and hydrochloric acid in a ratio of $3: 1$ on a hot plate. At the end of complete digestion it was filtered using a Whatman filter paper No. 1 into a $50 \mathrm{~mL}$ volumetric flask and made up to mark with distilled water. Metals concentrations were determined by Atomic Absorption Spectrophotometer.

\section{Preparation of extracts}

Exactly five Hundred gramms (500 g) of the leaves of $C$. pulcherrima were exhaustively macerated separately in 3 litres of methanol for 98 hours. The resultant mixture was filtered using cheese cloth and then Whatman's (No. 1) filter paper and the filtrate concentrated to dryness in vacuum at $40^{\circ} \mathrm{C}$ using rotary evaporator.

\section{Experimental animals}

Swiss mice $(18-24 \mathrm{~g})$ of either sex obtained from the University of Benin, Edo state, Nigeria were used for the study. The animals were kept in plastic cages at room temperature and moisture, under naturally illuminated environment of 12:12 hour dark/light cycle. They were fed on standard 
diet and had water ad libitum according to the NIH Guide for the care and use of laboratory Animals.

\section{Parasite inoculation}

Plasmodium berghei was obtained from the National Institute of Medical Research (NIMR), Lagos, Nigeria. Each mouse used in the experiment was infected intraperitoneally with 0.1 $\mathrm{mL}$ of infected blood containing about $1 \times 10^{7} \mathrm{P}$. berghei - parasitized erythrocytes. The inoculum consisted of $5 \times 10^{7} P$. berghei - parasitized erythrocytes per $\mathrm{mL}$. This was prepared by determining both the percentage parasitaemia and the erythrocytes count of the donor mouse and diluting the blood with isotonic saline in proportions indicated by both determinations.

\section{Preparation of giemsa solution}

Giemsa powder $(3.5 \mathrm{~g})$ was dissolved in a mixture of $250 \mathrm{~mL}$ of glycerol and $250 \mathrm{~mL}$ of methanol. The procedure was done in a dark room. The solution was poured in a dark reagent bottle and kept in a dark cupboard for a week.

\section{Preparation of phosphate buffer saline (pbs)}

Sodium dihydrogen phosphate $(10.9 \mathrm{~g})$ and $3.2 \mathrm{~g}$ of disodium hydrogen phosphate were dissolved in distilled water and the solution was made up to $1000 \mathrm{~mL}$ using distilled water. The $\mathrm{pH}$ of the solution was adjusted to 7.2 using dilute solution of $\mathrm{NaOH}$.

\section{Evaluation of suppressive activity of extract on early infection (4 day test)}

This test was used to evaluate the antiplasmodial activity of the leave extract and chloroquine against early $P$. bergheiberghei infection in mice. On the first day (D1), twenty-five Swiss albino mice were inoculated (intraperitoneally) with $P$. berghei parasitized erythrocyte $(0.1 \mathrm{~mL}$ of infected blood containing about $1 \times 10^{7} P$. bergheiberghei - parasitized erythrocytes) and randomly divided into five groups (Group A, B, C, $\mathrm{D}$ and $\mathrm{E}$ ) of five animals each and treated for the next four consecutive days (D1 - D4). Groups A, $\mathrm{B}$ and $\mathrm{C}$ received daily doses of the extract (200, 400 and $800 \mathrm{mg}$ of extract $/ \mathrm{kg}$ body weight of animal respectively) by oral route, group $\mathrm{D}$ received no treatment, while group $\mathrm{E}$ received 5 $\mathrm{mg} / \mathrm{kg}$ of chloroquine daily by oral route. The required dose was given according to the weight of the animal two hours after inoculation of parasites on D1, then once daily for three more days (D2 D5) [24].

\section{Evaluation of parasitaemia}

On day five (D5) of the study, thick and thin films were prepared with blood collected from the tail of each mouse. The thin film was fixed with methanol and both films were stained with Giemsa and the thin blood films of infected and treated mice were examined for parasitaemia level under the microscope from day five through day eight (D5 - D8). The stained slides were mounted in oil immersion. Red blood cells were counted in 10 fields and the parasitized also noted. The percentage parasitaemia $(\mathrm{Pp})$ in a group was calculated as:

$\mathrm{Pp}=\frac{\text { number of parasitised red blood cells }}{\text { total number of red blood cells }} \times 100$

The average percentage suppression for each dose of each extract was calculated in comparison to controls as follows:

Average $\%$ suppression $=\frac{X-Y}{X} \times 100$

Where, $X=$ Average $\%$ parasitaemia negative control

$\mathrm{Y}=$ Aaverage $\%$ parasitaemia treated groups.

\section{Ferric reducing antioxidant power (FRAP) analysis}

Prepared FRAP solution $(3.6 \mathrm{~mL})$ was added to distilled water $(0.4 \mathrm{~mL})$ and incubated at ambient temperature about $37^{\circ} \mathrm{C}$ for 5 minutes. Then this solution mixed with unknown concentrations of the plant extract $(80 \mu \mathrm{L})$ and incubated for 10 mins at about $37^{\circ} \mathrm{C}$. The absorbance of the reaction mixture was measured at $593 \mathrm{~nm}$ using the UVVisible spectrometer. Ferrous sulphate standard was prepared which was used for the construction of calibration curve of Absorbance against concentrations $(0.1,0.2,0.4,0.6,0.8,1.0)$ from which the various concentrations of the fractions of the leaf extract were determined at a known absorbance [25].

\section{Results and Discussion}

The results obtained from the in vivo antimalarial studies, ferric reducing antioxidant power and elemental analysis of the extract from the leaves of C. pulcherrima are shown in Table 1, 2, 3 and 4 
below. The calibration curve and experimental plot are also shown in Figure 1and 2 below.

Percentage yield of the extract

The percentage yield of the leaf extract of $C$. pulcherrima obtained was $15.83 \%$.
Elemental analysis of leaves of $C$. pulcherrima Some heavy metals in the leaves of $C$. pulcherrima were determined using Atomic Absorption spectrophotometer (AAS).

Table 1-Elemental analysis of the Leaves of C. pulcherrima

\begin{tabular}{lcc}
\hline Elements & Wavelenght $(\mathrm{nm})$ & Amount $(\mathrm{ppm})$ \\
\hline Sodium $(\mathrm{Na})$ & 589.3 & $20.27 \pm 0.12$ \\
Iron $(\mathrm{Fe})$ & 248.3 & $13.50 \pm 0.08$ \\
Calcium $(\mathrm{Ca})$ & 422.7 & $9.0 \pm 0.14$ \\
Copper $(\mathrm{Cu})$ & 324.7 & $0.30 \pm 0.08$ \\
Lead $(\mathrm{Pb})$ & 283.2 & - \\
\hline \multicolumn{2}{c}{ The concentration $(\mathrm{ppm})$ of lead was below detection limit }
\end{tabular}

\section{Comparison of \%parasitaemia of the leaves extract of $C$. pulcherrima and standard drug (chloroquine)}

Table 2-Effect of the extracts and standard drug (chloroquine) on Plasmodium berghei NK65

\begin{tabular}{llcccc}
\hline \multirow{2}{*}{ Treatment } & $\begin{array}{c}\text { Dosage } \\
(\mathrm{mg} / \mathrm{kg})\end{array}$ & $\mathrm{D}_{5}(\% \pm \mathrm{SD})$ & $\mathrm{D}_{6}(\% \pm \mathrm{SD})$ & $\mathrm{D}_{7}(\% \pm \mathrm{SD})$ & $\mathrm{D}_{8}(\% \pm \mathrm{SD})$ \\
\hline No treatment & & $5.23 \pm 0.59$ & $7.86 \pm 0.44$ & $10.25 \pm 0.40$ & $13.28 \pm 0.25$ \\
Extract & 200 & $2.90 \pm 0.22$ & $4.02 \pm 0.13$ & $6.21 \pm 0.14$ & $10.78 \pm 0.23$ \\
Extract & 400 & $2.53 \pm 0.16$ & $3.98 \pm 0.21$ & $6.03 \pm 0.16$ & $9.82 \pm 0.31$ \\
Extract & 800 & $2.01 \pm 0.15$ & $3.21 \pm 0.17$ & $5.61 \pm 0.27$ & $8.65 \pm 0.22$ \\
Chloroquine & 5 & $0.25 \pm 0.06$ & $0.65 \pm 0.14$ & $1.14 \pm 0.18$ & $1.83 \pm 0.22$ \\
Not treated group = Negative control, Extract = n-Hexane - ethyl acetate (50-50) VLC fraction of the leaves of $C$. pulcherrima, \\
Chloroquine = positive control, SD=Standard deviation.
\end{tabular}

\section{Antimalarial activity of leaves extract of $C$. pulcherrima}

Table 3- Mean survival time and \%Chemo-suppression of Plasmodium berghei bergheibythe Leave of C. pulcherrimaand Standard drug (chloroquine)

\begin{tabular}{|c|c|c|c|c|c|c|}
\hline \multirow[b]{2}{*}{ Treatment } & \multicolumn{5}{|c|}{ Average \%chemo-suppression } & \multirow[b]{2}{*}{$\begin{array}{c}\text { Mean Survival time } \\
\left(\mathrm{M}_{\mathrm{t}} \pm \mathrm{SD}\right) \text { days }\end{array}$} \\
\hline & $\begin{array}{l}\text { Dosage } \\
(\mathrm{mg} / \mathrm{kg})\end{array}$ & $\mathrm{D}_{5}(\%)$ & $\mathrm{D}_{6}(\%)$ & $\mathrm{D}_{7}(\%)$ & $\mathrm{D}_{8}(\%)$ & \\
\hline No treatment & & - & - & - & - & $14 \pm 3.22$ \\
\hline Extract & 200 & 44.55 & 48.85 & 39.41 & 18.83 & $27 \pm 2.49$ \\
\hline Extract & 400 & 51.63 & 49.36 & 41.17 & 26.05 & $24 \pm 2.72$ \\
\hline Extract & 800 & 61.57 & 59.16 & 45.27 & 34.86 & $22 \pm 2.49$ \\
\hline Chloroquine & 5 & 95.22 & 91.73 & 88.97 & 86.22 & $28 \pm 0.45$ \\
\hline
\end{tabular}


Table 4.FRAP analysis of various fractions of the leaf of $C$. pulcherrima

\begin{tabular}{lcc}
\hline \multicolumn{1}{c}{ Fractions } & Absorbance & Concentration \\
\hline 100\% ethyl-acetate & 1.049 & $314.90 \pm 3.94^{\mathrm{a}}$ \\
$50 \%$ ethyl-acetate:50\% n-hexane & 0.163 & $48.50 \pm 1.10^{\mathrm{b}}$ \\
$50 \%$ ethyl-acetate:50\% Methanol & 0.568 & $170.21 \pm 3.10^{\mathrm{c}}$ \\
$100 \%$ methanol & 0.211 & $63.10 \pm 1.02^{\mathrm{d}}$ \\
Crude & 0.493 & $147.932 .59^{\mathrm{e}}$ \\
\hline
\end{tabular}

Concentrations were reported in percentage mmole \pm SD of the various leaves fractions. Values with different alphabets indicate significant difference at $\mathrm{p}<0.05$

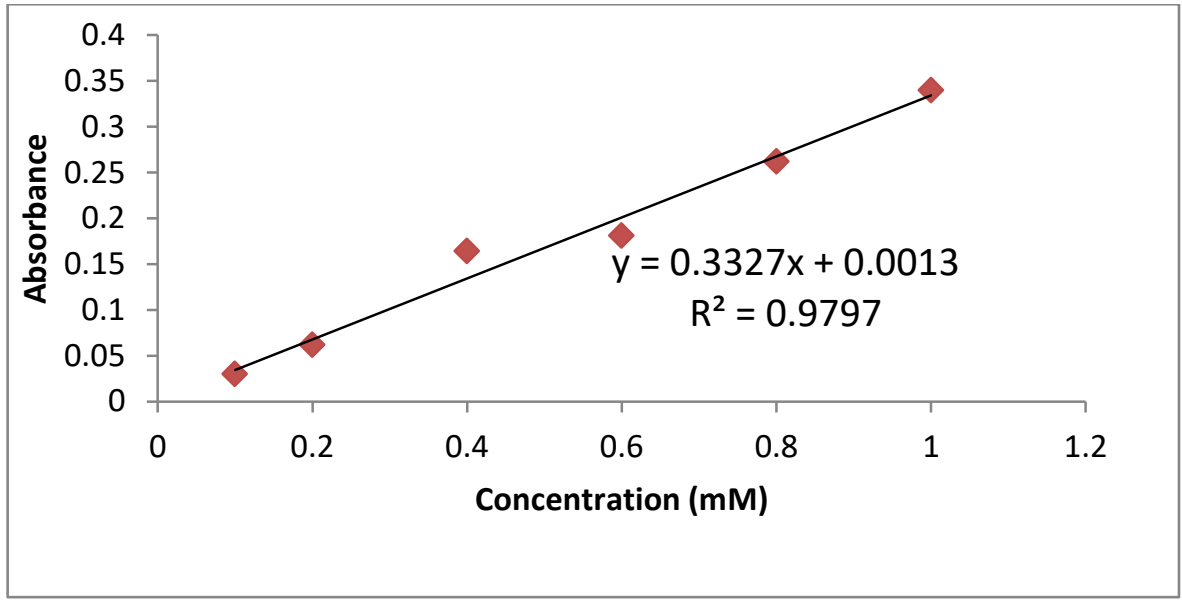

Figure 1Calibration curve for $\mathrm{FRAP}$ assay $\left(\mathrm{FeSO}_{4} \cdot 7 \mathrm{H}_{2} \mathrm{O}\right)$

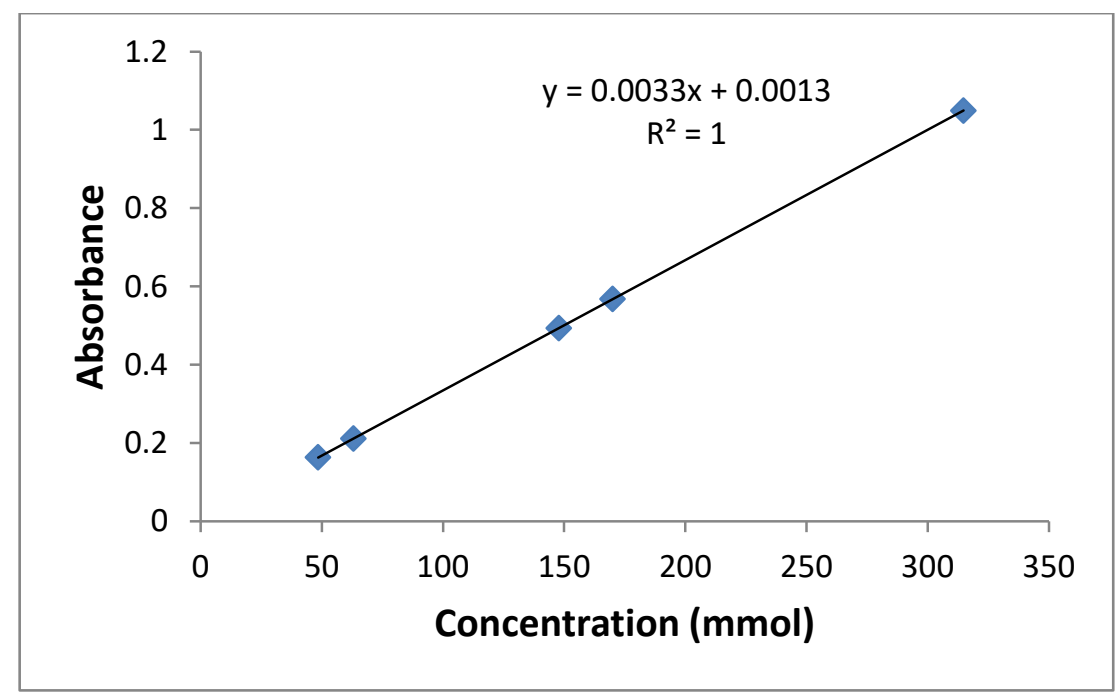

Figure 2: Absorbance against concentration for the various fractions of the extracts of leaf of $C$. pulcherrima

The chemo- suppressive activity of the extract (Table 3) shows that, the extract may have attacked the young Sporozoites cells, thereby inhibiting their growth or killing them like the 
standard drug that was used and/or the extract helped in boosting the immune system of the mice, re-enforcing it against microbial attack. The suppressive activity of the extract increased with increase in the dosage of the extract administered through $\mathrm{D}_{5}$ to $\mathrm{D}_{8}$ suggesting that the extract was more at an "advantage" over the parasite with increase in dosage, that is, an increase in dosage lead to a greater amount of bioactive component. However, there was a reduction in the activity from $D_{5}$ to $D_{8}$ for both the extract, suggestively this may be because some of the young parasite which escaped the period of treatment and grew to maturity and were subsequently released into the blood stream [19, 26, 27].

The antioxidant properties of the extract were evaluated. As mentioned earlier, anti-oxidants are vital in the mopping up of free radicals from the body. The extracts showed a considerable antioxidant effect from absorbance of $0.163 \mathrm{~nm}$ to $1.047 \mathrm{~nm}$ with $100 \%$ ethyl-acetate having the highest value. The concentration of the extracts are reported as mean \pm standard deviation as shown in (Table 4) from the plot of $\mathrm{Y}=0.0033 \mathrm{X}+0.0013$, thus the more intense the colour of the reagent, the higher the absorbance which shows a higher power of antioxidant capacity. The antioxidant activity of the plant extract could be as a result of phenolics and other phytochemicals present in the plant, majorly flavonoid [28]. From the analysis done, it shows that the leaves possess an antioxidant property capable of quenching free radicals. These antioxidants delay or inhibit cellular damage mainly through their free radical scavenging property [29].

The relative abundance of elements in the $C$. pulcherrima leaves was in the order of $\mathrm{Na}>\mathrm{Fe}>\mathrm{Ca}>\mathrm{Cu}$. There are several factors that affect the concentration of heavy metals and it includes bioaccumulation capacity, season, $\mathrm{pH}$, geographic factors, time of harvesting, age and salinity [30].According to the WHO, the permissible level of $\mathrm{Fe}, \mathrm{Pb}, \mathrm{Cd}, \mathrm{Cr}, \mathrm{Cu}, \mathrm{Ni}$, and $\mathrm{Zn}$ in medicinal plant and food is $20,10,1,1.5,10$, 15 , and $50 \mathrm{ppm}$, respectively [31].This study has shown that Lead concentration was below detectable limit, while the concentrations of $\mathrm{Fe}$ and $\mathrm{Cu}$ were within the limit of the WHO.In humans, Fe plays an important role in red blood cell production and is used against anemia, tuberculosis, and growth disorder [32].Cu helps in absorption of iron. It is also used for cellular defense, protecting mucus membrane and preventing anemia, osteoporosis, delayed wound healing and the development of aortic aneurysms, and loss of hair colour [33]. $\mathrm{Pb}$ is a non-essential trace element and has a detrimental effect on the human body. $\mathrm{Pb}$ poisoning causes convulsions, chronic hepatitis, Central Nervous System disorder, anemia, and kidney damage and reduces fertility and delayed puberty [34].

\section{Conclusion}

It has been shown from this study that $C$. pulcherrima extract and fractions contain bioactive components that could be used for the treatment of malaria. There was a dose dependent increase in percentage chemo-suppression of the parasites by the different groups with maximum effect at $800 \mathrm{mg} / \mathrm{kg}$. It was also revealed from the study that the $100 \%$ ethyl acetate extract had the highest concentration and thus having the highest antioxidant power as compared to other fractions. The leaf extract also exhibited concentrations of elements and heavy metals within the limits given by the WHO with no trace of $\mathrm{Pb}$ which is highly desirable. Further studies to isolate the various bioactive components and identify the compounds are being carried out.

\section{References}

1. R.W. Snow, C.A. Guerra, A.M. Noor, H.Y. Myint, S.I. Hay (2005). The global distribution of clinical episodes of Plasmodium falciparum malaria. Nature, 434(7030), 214-217.

2. CDRJE. LaMar. (2000). II. Navy Medical Department Pocket Guide to Malaria Prevention and Control. Navy Environmental Health Center, TechnicalManual NEHC-TM PM, 6250.1

3. A. Falodun, V. Imieje, O. Erharuyi, J. Ahomafor, P. Langer, M. Jacob, S. Khan, M. Abaldry, and M. Hamann.(2014). Isolation of antileishmanial, antimalarial and antimicrobial metabolites from Jatrophamultifida. Asian PacificJournal ofTropicalBiomedicine,4(5):374-378.

4. S.S. Patel, N.K. Verma, C. Chatterjee, and K. Gauthaman.(2010). Screening of Caesalpinia pulcherrima Linn Flowers for Analgesic and Anti-inflammatory Activities. International 
Journal of Applied Research in Natural Products, 3 (3), 1-5.

5. G. A. Agbor, D. Kuate, and J. E. Oben (2007). Medicinal plants can be good source of antioxidants: case study in Cameroon, Pakistan Journal of Biological Sciences, 10 (4) , 537-544.

6. G. Cao, S. L. Booth, J. A. Sadowski, and R. L. Prior (1998). Increases in human plasma antioxidant capacity after consumption of controlled diets high in fruit and vegetables, American Journal of Clinical Nutrition, 68 (5), 1081-1087.

7. S. S. Leonard, D. Cutler, M. Ding, V. Vallyathan, V. Castranova, and X. Shi (2002). Antioxidant properties of fruit and vegetable juices: more to the story than ascorbic acid, Annals of Clinical and Laboratory Science, 32 (2), 193-200.

8. S. Naskar, A. Islam, U. K. Mazumder, P. Saha, P. K. Haldar, and M. Gupta (2010). In vitro and in vivo antioxidant potential of hydromethanolic extract of phoenix dactylifera fruits, Journal Scientific Research, 2 (1), 144-157.

9. H. Sies, (1991). Oxidative stress: an introduction, in Oxidative Stress: Oxidants and Antioxidants, H. Sies, Ed., pp. 15-22, Academic Press, London, UK.

10. K. Becker, L. Tilley, J. L. Vennerstrom, D. Roberts, S. Rogerson, and H. Ginsburg (2004). "Oxidative stress in malaria parasite-infected erythrocytes: host-parasite interactions," International Journal for Parasitology, 34 (2), 163-189.

11. I. A. Clark and N. H. Hunt (1983). Evidence for reactive oxygen intermediates causing hemolysis and parasite death in malaria, Infection and Immunity, 39 (1), 1-6

12. P. G. Kremsner, B. Greve, B. Lell, D. Luckner, and D. Schmid (2000). Malarial anaemia in African children associated with high oxygen-radical production," Lancet, $\mathbf{3 5 5}$ (9197), 40-41.

13. M. Guha, S. Kumar, V. Choubey, P. Maity, and U. Bandyopadhyay, (2006). Apoptosis in liver during malaria: role of oxidative stress and implication ofmitochondrial pathway, FASEB Journal, 20 (8) E439-E449.

14. S. M. Potter, A. J. Mitchell, W. B. Cowden (2005). Phagocytederived reactive oxygen species do not influence the progression of murine blood-stage malaria infections," Infection and Immunity, 73 ( 8), 4941-4947.

15. C. C. Keller, P. G. Kremsner, J. B. Hittner, M. A.Misukonis, J. B. Weinberg, and D. J. Perkins, (2004). Elevated nitric oxide production in children with malarial anemia: hemozoin-induced nitric oxide synthase type 2 transcripts and nitric oxide in blood mononuclear cells, Infection and Immunity, 72 (8), 4868-4873.

16. M. Sohail, A. Kaul, M. Raziuddin, and T. Adak (2007). Decreased glutathione-Stransferase activity: diagnostic and protective role in vivax malaria," Clinical Biochemistry, 40 (5-6), 377-382.

17. A.A. Hamid, O.O. Aiyelagba, L.A. Usman, O. M. Ameen, A. Lawal A. (2010). Antioxidants: its Medicinal and Pharmacological Applications. Africa Journal of Pure And Applied Chemistry 4(8): 142-151

18. R. Gautam, A. Saklani, and S.M. Jachak. (2007). Indian medicinal plants as a source of antimycobacterial agents. Journal of Ethnopharmacology, 110:200-234.

19. O.K. Ogbeide, V.O. Dickson, R.D. Jebba, D.A. Owhiroro, M.O. Olaoluwa, V.O. Imieje, O. Erharuyi, B.J. Owolabi, P. Fasinu and A. Falodun (2018). Antiplasmodial and Acute Toxicity Studies of Fractions and CassaneType Diterpenoids from the Stem Bark of Caesalpinia pulcherrima (L.) Sw. Tropical Journal of National Product Research; 2(4):179-184.

20. S.P.Ambasta.(1998).EditorThe wealthof India, raw materials.Publication and information directorate, CSIR; 13-14 p.

21. G.S. Chakraborthy, R.S. Badujar, and C.R. Pardeshi. (2009). Analgesic activity of chloroform extract of Caesalpinia pulcherrima. Journal of Pharmaceutical Research,2:1199-1200.

22. R. Gautam, A. Saklani, and S.M. Jachak. (2007). Indian medicinal plants as a source of antimycobacterial agents. Journal of Ethnopharmacology, 110:200-234.

23. L.C. Chiang,W. Chiang, M.C. Liuand C.C. Lin.(2003). In vitro antiviral activities of Caesalpinia pulcherrima and its related flavonoids. Journal of Antimicrobial Chemotherapy, 52:194-198. 
24. D.J. Knight and W. Peters.(1980). The antimalarial action of Nbenzyloxydihydrotriazines, the action of clociguanil (BRL50216) against rodent malaria and studies on its mode of action. Annals of Tropical Medicine and Parasitology, 74: 393-404.

25. I.F.F. Benzie and J.J. Strain. TheFerric reducing ability of plasma (FRAP) as a measure of "antioxidant power": the FRAP assay. Analytical Biochemistry.239:70-76.

26. M.C. Jonville,H. Kodja, L. Humeau, J. Fournel, P.De Mol, M. Cao, L. Angenot and M. Frederich (2008). Screening of medicinal plants from reunion island for antimalarial and cytotoxic activity. Journal of Ethnopharmacology, 120:382-386.

27. R. Pink, A. Hudson, M.A. Mouries and M. Bending. (2005). Opportunities and challenges in antiparasitic drug discovery. National Revised Drug discovery,4(9):727-740.

28. A.R.

Gohari,H.Hajimehdipoor,S.Saeidnia,Y.Ajania ndA.Hadjikhoondi.(2011).Antioxidant activity of some medicinal species using FRAP assay. 37 winter.

29. B. Halliwell. How to characterize an antioxidant- An update.Biochemical Societal Symptoms, 61:73-101.

30. V. Talbot and A.Chegwidden.(1982). Cadmium and other heavy metal concentrations in selected biota from Cockburn Sound, Western Australia. AustralianJournal of Marsh and Freshwater Research, 33:779-88.

31. Evaluation of certain food additives and contaminants.(1989). Thirty-third report of the joint FAO/WHO expert committee on food additives. World Health Organization Technical Report Service,776:1-64.

32. CEVA. (2014).Edible Seaweed and French Regulation - Synthesis Made by CEVA. France: CEVA.

33. K. Rajendran, P. Sampathkumar, C. Govindasamy, M. Ganesan, R. Kannan and L. Kannan.(1993). Levels of trace metals (Mn, $\mathrm{Fe}, \mathrm{Cu}$ and $\mathrm{Zn}$ ) in some Indian seaweeds. March Pollution Bulletin, 26:283-5.

34. M. Ayaz, M. Junaid, F. Subhan, F. Ullah, A. Sadiqand S. Ahmad (2014). Heavy metals analysis, phytochemical, phytotoxic and anthelmintic investigations of crude methanolic extract, subsequent fractions and crude saponins from Polygonumhydropiper L. BMC Complement Alternative Medicine, 14:465 